\title{
Uitdagingen voor onderzoek naar honoursonderwijs
}

\author{
Marca Wolfensberger \& Albert Pilot
}

Het applaus van de bezoekers van het Amsterdams Concertgebouw was overweldigend. De 120 jonge muzikanten van het Boston Philharmonic Youth Orchestra leken er beduusd van. Hun dirigent, Benjamin Zander, had het Concertgebouw al een jaar geleden vastgelegd voor dit optreden. Overigens, ruim vóór zijn eerste repetitie met dit orkest. Zulk een aanpak past bij zijn filosofie die zich richt op de mogelijkheden van de toekomst en de kracht van de uitdaging (Zander \& StoneZander, 2002). Het orkest wist onder zijn bezielende leiding, zijn hoge verwachtingen van de jonge muzikanten en zijn vertrouwen in hun kwaliteiten de uitvoering van Mahler tot een succes te maken.

Honoursonderwijs biedt niet alleen uitdagingen aan studenten, maar ook aan docenten en onderwijsonderzoekers. Onderzoek naar de leerprocessen van honoursstudenten, hun motivatie en betrokkenheid, hun aanpak en de begeleiding daarbij door docenten, kunnen leiden tot nieuwe inzichten in de werking van het hoger onderwijs en tot nieuwe mogelijkheden en kansen voor innovatie van het universitair onderwijs en het hoger beroepsonderwijs. De artikelen in dit themanummer van het Tijdschrift voor Hoger Onderwijs geven nieuwe perspectieven op de uitdagingen voor de kwaliteit en kwantiteit van het honoursonderwijs en de relatie met het regulier onderwijs. Deze artikelen geven tegelijk ook aanleiding tot nieuwe onderzoeksvragen. Na een schets van de ontwikkelingen in het onderzoek van de afgelopen jaren, geven we aan de hand van een model en de artikelen in dit themanummer een stand van zaken van recente ontwikkelingen in enkele thema's. Ook formuleren we vragen voor toekomstig onderzoek en schetsen we kansen voor innovaties.

\section{Uitdagingen door de tijd heen}

Het onderzoek naar honoursprogramma's startte in Nederland rond de eeuwwisseling (Van Eijl, Faber, Jorissen, \& Pilot, 1999; Wolfensberger et al., 2003) en was binnen Europa vernieuwend. Het liep bijna gelijk op met de opkomst van het honoursonderwijs. Het onderzoek werd vooral uitgevoerd door mensen van diverse instellingen die zelf ook honoursonderwijs gaven en regelmatig samenkwamen als interdisciplinair team (Van Wissen \& Wolfensberger, 2006). Zo werd ook in die tijd het Plusnetwerk ter bevordering van het honoursonderwijs in Nederland gestart en in 2001 formeel opgericht ('+netwerk'). Honoursstudenten

* Marca Wolfensberger (m.v.c.wolfensberger@pl.hanze.nl) is werkzaam bij de Faculteit Geowetenschappen, Universiteit Utrecht en is Lector aan de Hanze Hogeschool Groningen. Albert Pilot (a.pilot@uu.nl) is emeritus hoogleraar aan de Universiteit Utrecht. 
waren hier deel van en publiceerden ook over honours, zoals Harms \& Hogenstijn (2001). De beweging was klein en het hbo was nog niet opgenomen in het netwerk. Overigens werd het honoursonderwijs zeker nog niet overal op de universiteiten omarmd. Wel nam het aantal bezoekers van studiedagen gestaag toe met rond de 120 deelnemers aan de VSNU-Plusnetwerk-conferentie rond 'Het verleiden van talent in academia' (2004). Er werden gezamenlijke werkbezoeken aan Amerikaanse honoursprogramma's georganiseerd en congressen van de Amerikaanse National Honours Collegiate Council (NCHC) bezocht (Bergstra et al., 2005; Wolfensberger, Van Eijl, \& Pilot, 2003). Deze activiteiten zijn later door Sirius overgenomen (zie http:// www .siriusprogramma.nl), waardoor een breed landelijk netwerk gericht op honoursonderwijs en talentontwikkeling is ontstaan. Vanaf de start is er dus een sterke wisselwerking geweest tussen de ontwikkelingen van het Nederlandse honoursonderwijs en het onderzoek naar dit onderwijs (zie ook het eerste themanummer over excellentie van dit tijdschrift in 2010; en het boek Talent voor Morgen van Van Eijl, Wolfensberger, \& Pilot, 2010). Deze interactie werd verrijkt met internationale kennis, met name uit de Verenigde Staten, waar een lange honourstraditie bestaat (Brown, 2001, 2002; Long, 2012). Een hoogtepunt in de internationale uitwisseling van onderzoeksresultaten betreft het themanummer 'Honors around the Globe' van het Amerikaanse Journal National Collegiate Honors Council met bijdragen uit vele landen, waaronder tien Nederlandse vanuit verschillende onderzoeksgroepen (Long, 2012).

De vraag hoe het excellentieonderwijs goed kan functioneren, staat vanaf het begin centraal. Dus niet: werkt het? Maar juist: hoe zorgen we dat het werkt? Deze vragen kwamen mede voort uit de uitdagingen waar men zich voor gesteld zag door de anti-excellentiecultuur. Deze benadering heeft geleid tot specifieke vragen vanuit de onderwijspraktijk, zoals: wat is de missie van honoursonderwijs en hoe ondersteunt deze missie het onderwijs (Bartelds, Drayer, \& Wolfensberger, 2012)? Hoe kan de organisatie, de cultuur en de structuur van een onderwijsinstelling de ontwikkeling van excellentieonderwijs bevorderen (Coppoolse, Van Eijl, \& Pilot, 2013)? Hoe bevorder je de talentontwikkeling van de deelnemende studenten (Van Eijl, Pilot, Wolfensberger, \& Schreve-Brinkman, 2010) in samenspraak met de samenleving (Wijffels \& Wolfensberger, 2004; Van Eijl, Renique, \& Reimer, 2011)? Hoe kunnen docenten en studenten elkaar binnen het honoursonderwijs versterken, en is er sprake van een specifieke honoursdidactiek (Wolfensberger, 2012). Hoe kan de relatie versterkt worden tussen succes in de beroepspraktijk en het gevolgde (honours)onderwijs (Paans, Wijkamp, Wiltens, \& Wolfensberger, 2013; Scager et al., 2012; Van Dijk, 2012) en hoe denken honoursalumni daarover (Wolfensberger, Sweijen, Van Eijl, Hartog, \& Van der Vaart, 2010)?

De groei van de afgelopen twintig jaar van excellentieprogramma's en het begeleidende onderzoek laten een ware cultuurverandering zien, die als de stille revolutie in de zesjescultuur van het Nederlandse hoger onderwijs heeft plaatsgevonden (Van den Doel, 2007). Willen excelleren binnen je studie is geen individuele hobby meer, maar is een geïnstitutionaliseerde mogelijkheid. Vele onderwijsin- 


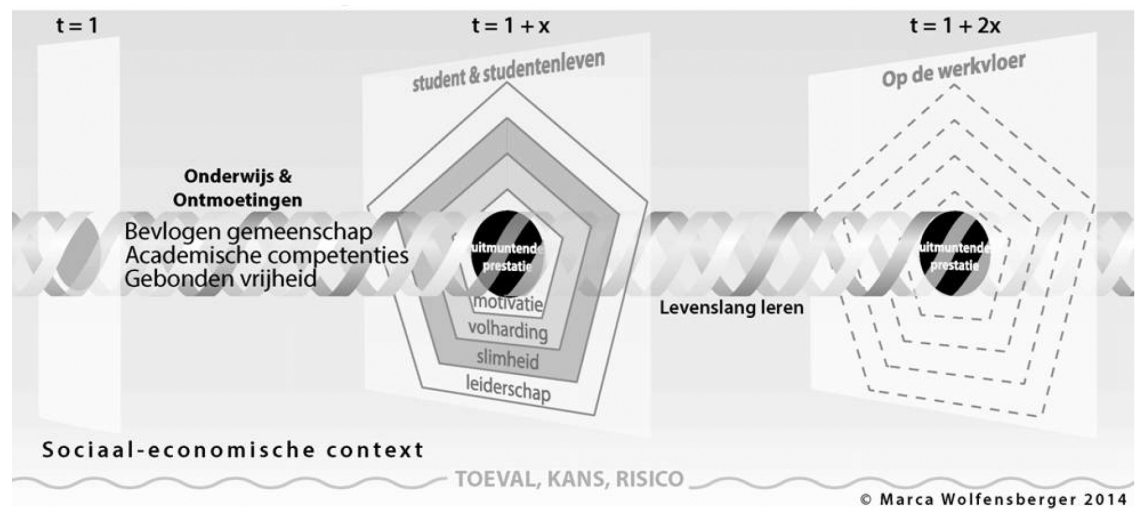

Figuur 1 Het Integratieve model van Excellente Prestaties: het IEPER-model

stellingen, zowel in het wo als het hbo, nemen nu in hun instellingsplannen en in de praktijk van het dagelijkse onderwijs de verantwoordelijkheid om onderwijs aan te bieden dat uitdagend is voor de studenten die meer willen en kunnen (Van Eijl, Wolfensberger, \& Van Tilborgh, 2004; Wolfensberger, De Jong, \& Drayer, 2012). Gesprekken over toelating en selectie gaan nu vaak over de juiste match van elke student met de juiste plek. Het hardop uitspreken van de vraag waarom de student gemotiveerd is voor een studie en wat het honoursonderwijs aantrekkelijk voor hem of haar maakt, zijn onderdelen van 'matching' zoals bijvoorbeeld bij de Universiteit Utrecht (zie http://matching-uu.wp.hum.uu.nl/). Uitblinken kreeg zelfs zoveel aandacht dat er al sprake is van een tegenbeweging over de prestatiegeneratie, die teruggrijpt op de oude cultuur van 'niet boven het maaiveld uit steken' en 'iedereen gelijk' (Van Baar, 2014). Gerichtheid op talentontwikkeling en uitmuntende prestaties is niet vrijblijvend en er zijn risico's mee verbonden, zoals elitevorming en de uitwassen van competitie. De factor risico is daarom ook meegenomen in het Integratieve model voor Excellente Prestaties (IEPER-model).

\section{Onderwijs en ontmoeting}

Het Integratieve model voor Excellente Prestaties (IEPER-model) van Wolfensberger (2011) is ontwikkeld om belangrijke aspecten van onderzoek en onderwijs over excellentiebevordering in hun samenhang zichtbaar te maken (zie figuur 1) en is daarom bruikbaar om dat ook voor de artikelen in dit themanummer te doen. Het IEPER-model laat zien welke aspecten van belang zijn om via (honours)onderwijs tot uitmuntende prestaties te komen. Die prestaties zijn een uitkomst van het handelen van studenten en docenten. Door handelingen laten studenten en docenten ook zien wie ze als persoon zijn en hoe ze zich ontwikkelen. Deze handelingen en persoonlijke ervaringen - ook buiten het formele onder- 
wijssysteem - van studenten en docenten zijn een belangrijk onderdeel van het honoursonderwijs. De persoonlijke ervaringen en relaties tussen studenten en docenten worden in het model aangegeven met 'onderwijs en ontmoeting'. Het honoursonderwijs draait in essentie om de groei in de ontmoeting. Door de intensieve samenwerking en interactie in dit onderwijs en de diversiteit aan persoonlijke inbreng en diversiteit van de personen, leveren deze ontmoetingen een belangrijke bijdrage aan de ontwikkeling van de studenten. Maar voor een vruchtbare bijdrage aan deze ontwikkeling moet de student eerst zichzelf en zijn of haar vak goed kennen. Daarna kan het gesprek met de ander tot ideeënrijkdom leiden en kunnen ook de eigen standpunten getoetst en verrijkt worden (Biesta, 2014; Sacks, 2007). De uitkomst van de ontmoeting kan dan transformatief zijn en kan bijvoorbeeld tot nieuwe inzichten, tot gedragsveranderingen of tot keuzeveranderingen bij toekomstige uitdagingen leiden.

Mede met het oog daarop wordt in het artikel van Van der Rijst en Wolfensberger (dit nummer) nagegaan welke opvattingen docenten hebben over de meerwaarde van honoursprogramma's voor studenten. Ook wordt nagegaan wat de consequenties daarvan zijn voor de professionalisering van honoursdocenten. Het gezamenlijke optrekken in onderzoek en het stimuleren van nieuwsgierigheid worden als meerwaarde van honoursonderwijs genoemd (Van der Rijst \& Wolfensberger (dit nummer); Wiegant, Scager, \& Boonstra, 2011).

\section{De docent en doceerstrategieën}

Het IEPER-model gaat nader in op strategieën in het onderwijs en de ontmoeting die kunnen leiden tot excellente prestaties. Opvallend in het honoursonderwijs is daarbij dat docenten en studenten in de ontmoeting een bevlogen gemeenschap creëren en daarin intensief en diepgaand aandacht besteden aan academische competenties (inhoud, vaardigheden en attitudes). In die gemeenschapsvorming worden gelegenheden geschapen om tot prestaties te komen die verwondering en bewondering kunnen oproepen bij medestudenten en docenten. Daarbij zijn strategieën nodig die autonomie ondersteunen (Vansteenkiste et al., 2012), in het IEPER-model van Wolfensberger aangeduid met 'vrijheid in gebondenheid' (zie figuur 1). Bij autonomie moet ook gedacht worden aan het creëren van ruimte voor initiatief, aan flexibiliteit bij personen en organisaties, en aan gelijkwaardigheid op de werkvloer (Van Gorp, Wolfensberger, \& De Jong, 2012; Wolfensberger, 2012). Ten Berge \& Van der Vaart laten in hun artikel in dit nummer, 'Honoursdidactiek in een leergang voor honoursdocenten', zien hoe deze drieslag van strategieën voor goede honoursdidactiek voor studenten - het creëren van een community, het ontwikkelen van academische competenties en het bieden van gebonden vrijheid (Wolfensberger, 2012) - werkzaam is in de opzet van een leergang voor docenten die honoursstudenten begeleiden. Ten Berge en Van der Vaart betogen dat het ontwerp van de leergang, dat gebaseerd is op deze strategieën, het succes van de leergang in termen van de leeropbrengst bepaalt. Het ontwikkelen en volgen van docentprofessionalisering voor honoursdocenten 
wordt gezien als een van de sleutels voor het verdere succes van honoursonderwijs. Docentprofessionalisering op het gebied van honoursondewijs krijgt in steeds meer instellingen prioriteit en is aanjager van netwerkvorming (Unck, Lammers, \& Lappia, 2014).

\section{De student}

Veel aandacht van onderzoekers is de afgelopen jaren uitgegaan naar de persoonskenmerken (zoals motivatie, volharding, slimheid en leiderschap, zie figuur 1) van de student die meer wil en kan dan het reguliere hoger onderwijs biedt. Deels is daarvoor kwantitatief onderzoek via vragenlijsten uitgevoerd, zowel in het wo (Scager, 2013), als in het hbo (Kool \& Wolfensberger en Kazemier, Offringa, Eggens \& Wolfensberger, beide artikelen in dit nummer), deels via exploratief, kwalitatief onderzoek naar het leerproces van honoursstudenten (Hermsen \& Coppoolse, in dit nummer). Dit laatste artikel is weliswaar exploratief en kleinschalig, maar biedt tevens een aanzet tot nieuw onderzoek naar details van de leerprocessen en persoonlijkheidsontwikkeling van deze studenten, die een grote diversiteit aan kenmerken vertonen. Dit verklaart wellicht dat de resultaten van grootschalig kwantitatief onderzoek in de vorm van gemiddelden van items in een vragenlijst en correlaties in een variantieanalyse soms onverwachte en moeilijk te interpreteren uitkomsten laten zien. Dat is bijvoorbeeld zichtbaar in de opvallende verschillen tussen studierichtingen die Scager et al. (2012) vonden en de mogelijke effecten van intrinsieke versus extrinsieke motivatie (Kazemier et al., in dit nummer). Ook de diversiteit in programma's en selectiecriteria (bijvoorbeeld programma's die gericht zijn op professionele excellentie versus liberal arts-programma's) kunnen een verklaring zijn voor de verschillen in resultaten van dit type onderzoek. De combinatie van kwalitatief onderzoek (waarbij de studenten zelf hun ervaringen en motieven in detail in interviews bespreken) en kwantitatief onderzoek onder gehele jaargroepen over langere tijd, lijkt ons een waardevol perspectief voor toekomstig onderzoek, waarbij dan ook de rol en taak van docenten een belangrijk onderdeel zal kunnen zijn. Recent is een eerste boekje met interviews met honoursstudenten van de Hogeschool van Amsterdam verschenen (Keuning, 2014). Van Eijl \& Pilot werken met honoursstudenten aan een uitgave met een groter aantal van dergelijke interviews.

\section{Latent talent}

Selectie van studenten, aannamebeleid en doorstroom zijn belangrijke onderwerpen binnen het excellentieonderwijs. 'Latent talent' is een thema dat recent aandacht heeft gekregen, vooral bij honoursprogramma's in het hbo, waar leerlingen van de havo (kunnen) instromen. Een deel van deze leerlingen voelt zich helemaal niet 'excellent' en er is sprake van onderbenut potentieel, ook in de bètavakken (Korpershoek, 2010). Andere studenten hebben via een leerweg van vmbo, havo, mbo hun ontwikkeling doorgemaakt, voordat ze de (on)mogelijkheden zien van 
talentontwikkeling in honoursprogramma's. De beeldvorming die studenten hebben over honoursonderwijs speelt mee in hun motivatie deel te nemen. Onderzoek naar (meta-)stereotypen, bijvoorbeeld percepties over het stereotype dat reguliere studenten hebben ten aanzien van honoursonderwijs of dat docenten hebben over honoursstudenten, kan informatie geven over aanmeldingsmotivaties van honoursstudenten. Factoren als diversiteit, gender, mindset en persoonlijkheid spelen mee bij de zelfontdekking dat iemand talent heeft en dit ook kan ontwikkelen. Soms gaat het dan om talenten waarvan zijzelf en hun omgeving zich eerder niet bewust waren (Van Eijl et al., 2013). Inzichten uit dit onderzoek zijn zeker ook relevant in de discussie rondom toptalent en de positie van honoursonderwijs. Haaks op de emancipatoire gedachte van het honoursonderwijs wordt het nu ook wel gezien als de "top van de piramide" (10 procent - het zogenoemde 'quartair onderwijs'), zoals omschreven in een recente scenariostudie voor de VSNU (Rathenau Instituut, 2014, p.35). Aandacht van onderzoekers en ontwikkelaars voor deze thema's is van belang voor de doelstellingen van de brede invoering van talentontwikkeling in het hoger onderwijs.

\section{Context en tijd}

Het IEPER-model duidt op het belang van de sociaal-economische context bij talentontwikkeling. Het artikel van Tiesinga \& Wolfensberger in dit nummer onderstreept de weerbarstigheid van cultuurverandering en duidt op de invloed van de context. De invloed van sociaal-economische en omgevingsfactoren op deelname aan en prestaties in honoursonderwijs verdient meer aandacht in het onderzoek en zal ook diversiteit op de agenda zetten. Ook de factor tijd is bij excellentiebevordering essentieel, ten eerste omdat de factor tijd (die in het IEPER-model in figuur 1 is aangegeven met ' $t=1$ ', en ' $t=1+x$ ') van belang is bij het leren reflecteren en om elkaar zinvol te ontmoeten. Tijd is ten tweede essentieel omdat veel tijd nodig is om kennis, vaardigheden en attitudes op een hoog niveau te brengen. Denk bij 'veel tijd' bijvoorbeeld aan de 10.000 uur deliberate practice die in een discipline nodig is, zoals uit het onderzoek van Ericsson naar voren komt (Ericsson, 2004). Maar tijd is ten derde ook een factor omdat talentontwikkeling door de hele onderwijsketen heen plaatsvindt. Passend bij de Nederlandse cultuur hechten we er waarde aan dat excellentieprogramma's aangeboden worden door de hele onderwijsketen heen, waarbij de grensovergang tussen voortgezet onderwijs en hoger onderwijs speciale aandacht vraagt (Van der Valk, Grunefeld, \& Pilot, 2011; Van der Valk, in press; Van Dijk, Meijer, \& Van der Valk, 2013). Het artikel van Haenen en Mol Lous (in dit nummer) verwijst naar nog een andere verbondenheid tussen hoger onderwijs en basisonderwijs, doordat zij ingaan op benodigde competentieontwikkeling in de docentenopleidingen voor het basisonderwijs. Overigens is het gewenst ook in de opleiding van vo-docenten aandacht te schenken aan de kennis, vaardigheden en attitudes van toekomstige vo-docenten ten aanzien van talentontwikkeling en excellentie. 


\section{Honourscultuur en honourscommunity's}

Vanaf de start van honoursprogramma's geven studenten en docenten aan dat de cultuur en community's in het honoursonderwijs een belangrijk onderdeel zijn van hun activiteiten. Tiesinga is daarom gestart met een onderzoek naar de honourscultuur en rapporteert in dit nummer over de eerste resultaten daarvan. Omdat het onderzoek zich beperkt tot één (hbo-)onderwijsinstelling is het zeker relevant om een dergelijk onderzoek ook uit te voeren in andere onderwijsinstellingen en andere types van honoursprogramma's. De kenmerken van honourscommunity's zijn onderzocht door Van Ginkel, Van Eijl en Pilot en beschreven in een artikel dat in dit nummer werd opgenomen. Ook dit onderzoek was kleinschalig en beperkt tot enkele cases in een klein aantal instellingen, hoewel ook gebruik gemaakt werd van interviews onder Amerikaanse studenten en docenten. Een uitbreiding van dit onderzoek ligt voor de hand en is wenselijk, mede gezien het belang dat deze community's hebben voor de honoursprogramma's en tegen de achtergrond van de moeilijkheden om community's te ontwikkelen. Die moeilijkheden worden vaak genoemd bij programma's waaraan studenten van verschillende opleidingen deelnemen, of studenten die niet op een campus wonen en weinig contacturen hebben, waardoor ze elkaar weinig ontmoeten.

\section{Toetsing}

Het onderwerp 'kwaliteitszorg' heeft in het empirisch onderzoek weinig aandacht gekregen, maar is wel een belangrijk onderwerp van discussie, zowel in de Verenigde Staten als in Nederland. Moet er een procedure met duidelijke criteria komen om een zekere garantie van kwaliteit te hebben (Tiesinga, 2013)? Zie bijvoorbeeld Van Eijl, Pilot en Heemskerk (2013) met verwijzingen naar de discussie in de Amerikaanse National Honors Collegiate Council (NCHC), over de voor- en nadelen van accreditatieprocedures van kwaliteitszorg. De wederzijdse site visits die in Nederland zijn opgezet, zijn ook een auditvorm (Marx, Elzinga, Haaren, \& Bastiaens, 2014) waarvan de effecten getoetst kunnen worden. Daarbij aansluitend vraagt ook het thema 'beoordeling van leerresultaten' om nadere aandacht van onderzoekers. Hoe kan op een valide en betrouwbare manier het niveau van honoursleerresultaten worden vastgesteld, en welke beoordelingsmethoden doen recht aan de mate van complexiteit en zelfstandigheid die kenmerkend is voor honoursresultaten (zie Coppoolse et al., 2013)?

\section{Leven lang leren}

Door de ontwikkelingen in hbo-honoursprogramma's is zichtbaar geworden dat professionele excellentie een apart thema is, dat apart aandacht verdient in het onderzoek en de professionele ontwikkeling van docenten. Het boek Hoogvliegers, ontwikkeling naar professionele excellentie (Coppoolse, Van Eijl, \& Pilot, 2013) maakt zichtbaar dat met de ontwikkeling van honoursprogramma's, die daarop gericht zijn, een weg is ingeslagen die afwijkt van de traditie in de Amerikaanse 
honoursprogramma's. Deze laatste hebben vaak het karakter van een liberal artsprogramma en besteden weinig aandacht aan een professie, die in de VS vaak pas na het bachelorprogramma aan de orde komt, terwijl honoursprogramma's in de Amerikaanse masterprogramma's nauwelijks bestaan (Van Ginkel, Van Eijl, Pilot, \& Zubizarreta, 2012). Het IEPER-model wijst op de doorlopende leerlijn en op het belang van een leven lang leren wil men komen tot uitmuntende prestaties waar men tevreden over is. Verder onderzoek naar professionele excellentie, ook in het Nederlandse wo, bijvoorbeeld bij medische en juridische opleidingen, is gewenst om zo de relatie tussen de beroepspraktijk, excellent presteren en een specifiek aanbod van honoursactiviteiten te onderbouwen.

\section{Kernwaarden van honours}

Vanaf de start van honoursonderwijs wordt gesteld dat honourseducatie een rol kan spelen in het opleiden van leiders van de toekomst (Aydelotte, 1944). Leiderschap is ook opgenomen in het IEPER-model (zie figuur 1). Daarmee samenhangend is in Nederland ook Bildung naar voren gekomen als een belangwekkend thema voor (honours)onderwijs. Dit wordt vaak in samenhang gebracht met liberal arts en 21st century skills, onder de vlag van een mensgerichte benadering van het onderwijs (De Graaf, in press; Lutters, 2013). Overigens wordt dit thema in de recente scenariostudie voor de Nederlandse universiteiten als een onderdeel genoemd voor alle hoger onderwijs (Rathenau Instituut, 2014). Het doel van Bildung past bij burgerschapseducatie en wordt ook wel omschreven als een focus op maatschappelijk verantwoordelijkheidsgevoel, empathie of ethische sensitiviteit. In recent promotieonderzoek is gekeken of honoursstudenten in het hoger onderwijs verschillen van reguliere studenten wat betreft ethische sensitiviteit, wat een aspect van morele ontwikkeling is. Het blijkt dat ook op de leeftijd van ongeveer twintig jaar studenten met bovengemiddelde vermogens en motivatie gemiddeld hoger scoren op ethische sensitiviteit (Schutte, Wolfensberger, \& Tirri, in press). In vervolgonderzoek wordt onderwijs op het gebied van wereldburgerschap, waarin morele ontwikkeling is ingebed, ontworpen voor deze groep.

\section{De kracht van de uitdaging}

Toch moeten we op grond van de OECD/PISA/TIMMS-rapporten ook constateren dat durven en willen uitblinken zeker nog geen gemeengoed is in het Nederlandse onderwijs (OCW, 2013, 2014). Het blijft een kunst om het willen excelleren te combineren met de Nederlandse 'moet kunnen'-houding (Pleij, 2010). De onderwijsontwikkelingen en het onderzoek naar excellentiebevorderend onderwijs in Nederland en ook in Europa laten wel zien dat docenten en onderzoekers samen op zoek zijn naar steeds beter kwalitatief hoogwaardig onderwijs voor getalenteerde en gemotiveerde studenten (Van Tassel-Baska, 2013).

Docenten blijven vragen houden over excellentieonderwijs, onder andere wat ze kunnen doen om studenten te helpen leren excelleren (Coppoolse, Van Eijl, \& 
Pilot, 2013), maar ook of extra aandacht en dus ook geld voor de betere student wel eerlijk en nodig is. Amerikaanse docenten worstelen eveneens met dergelijke vragen. Deels ligt de meerwaarde van honoursonderwijs in de laboratoriumfunctie van het honoursonderwijs voor innovaties in het reguliere onderwijs. Docenten gebruiken hun ervaringen met honoursonderwijs ook als proeftuin en zij experimenteren bijvoorbeeld met nieuwe vakinhouden, uitdagende opdrachten of nieuwe onderwijsvormen (Wolfensberger, Van Eijl, \& Pilot, 2012; Wolfensberger 2012). Onderzoek naar de effecten van innovaties in het honoursonderwijs staat nog in de kinderschoenen.

Tiesinga \& Wolfensberger stellen in dit nummer dat de cultuur van honoursstudenten een stimulans kan zijn voor cultuurverandering binnen een hele instelling, maar dat er ook aspecten van cultuur zijn die uitstralingseffecten juist kunnen belemmeren. Nader onderzoek naar mogelijke uitstralingseffecten en de meerwaarde van het honoursonderwijs is wenselijk. Het onderzoek dat ITS, ROA en CHEPS in opdracht van het ministerie van OCW doen om de meerwaarde van het Sirius-programma in beeld te brengen, kan hiervoor nieuwe aanknopingspunten bieden (ITS, 2013). Het lopende onderzoek van Wolfensberger naar programma's voor getalenteerde studenten in het hoger onderwijs in Europa laat zien dat internationale vergelijkingen verdiepende inzichten kunnen geven in de factoren die de ontwikkeling van honoursonderwijs beïnvloeden. Meer internationale vergelijkingen (Györi, 2012) zijn in het belang van alle betrokkenen, niet het minst voor studenten die daardoor gerichter ook buiten het eigen land honoursprogramma's kunnen gaan kiezen. Het vormen van internationale onderzoeks- en onderwijsnetwerken zal het honoursonderwijs versterken.

De toenemende aandacht voor talent en de ontwikkelingen van honoursprogramma's en honourscolleges van de afgelopen twintig jaar staan niet op zichzelf (De Boer, Minnaert, \& Kamphof, 2013), zoals ook bleek in het eerdere themanummer over talentontwikkeling en excellentie van dit tijdschrift ( TvHO 2010). Het onderwijs, maar ook het werkveld en de politiek wijzen op het belang van differentiatie en op de mogelijkheden voor ontwikkeling van talent. De overheid laat zien met de brief van de staatssecretaris (OCW, 2014) dat aandacht voor uitblinken over de hele linie van het onderwijsaanbod en door de hele keten heen nodig is. Het gaat daarbij niet alleen over cognitief talent of hoogbegaafden, maar ook om andere talenten zoals sport of muziek. Dit zien we ook terug in het door NWO-NRO gefinancierde mixed methods-onderzoek naar excellentie en samenwerken in het hoger onderwijs waar expliciet aandacht is voor objectief gemeten creativiteit, naast aandacht voor cognitie en persoonlijkheid (Pullen, Griffioen, \& Schoonenboom, 2013). Gaat het bij excellent onderwijs om een selecte groep van high potentials, die alleen nog maar gedetecteerd moet worden, of gaat het om het scheppen van een context waarin elk talent, groot of klein, tot maximale ontplooiing gebracht kan worden (Platform Bèta-Techniek, 2014)? Wat willen we teweegbrengen met ons honoursonderwijs en hoe zorgen we dat het werkt?

Het publiek verliet geroerd de zaal van het Concertgebouw. "Ik pak toch mijn gitaarles weer op", hoorde ik naast me. De harpiste belde naar huis met trots en 
ook heimwee, deze eerste keer van huis. De talentscout wist genoeg en noteerde een naam. En Benjamin Zander vertelde ons over de transformerende ervaringen van de spelers. Zij hadden de kracht ervaren van de uitdaging te geloven in hun mogelijkheden. Samen konden ze de kern van zichzelf laten horen in een gemeenschappelijk symfonie waardoor ook het publiek meegenomen werd in een positief geloof in de toekomst.

\section{Referenties}

Aydelotte, F. (1944). Breaking the academic lock step. The development of honors work in American colleges and universities. New York, NY: Harper \& Brothers Publishers.

Bartelds, V., Drayer, A.L., \& Wolfensberger, M.V.C. (2012). Mission, performance indicators and assessment in US-honors: a view from the Netherlands. Journal of the National Collegiate Honors Council, 13(2), 129-145.

Bergstra, J., Keestra, M., Van Leijen, M., Pilot, A., Schram, A., Van Wissen, G., \& Wolfensberger, M.V.C. (2005). Honoursprogramma's en -colleges, van Aristoteles tot Undergraduate Research Programs, verslag van een bezoek aan Honors Programs en Honors Colleges in en rond New Orleans en aan de National Collegiate Honors Conference in November 2004. Amsterdam: Universiteit van Amsterdam.

Biesta, G. (2014). The Beautiful Risk of Education (Interventions: Education, Philosophy, and Culture). Boulder, Co.: Paradigm Publishers.

Brown, E.R. Jr. (2001). Level differentiation in the United States. Part I: a brief history of honors. The National Honors Report, 22, 48-54.

Brown, E.R. Jr. (2002). Level differentiation in the United States. Part II: level differentiation and honors programs. The National Honors Report, 22, 35-44.

Coppoolse, R., Van Dijk, T., Ter Woord, R., Weerheijm, R, Vroegindeweij, D., Van Eijl, P.J., \& Pilot, A. (2013). Excellentieprofielen in het hoger beroepsonderwijs. In R. Coppoolse, P.J. Van Eijl \& A. Pilot (red.), Hooguliegers, ontwikkeling naar professionele excellentie (pp. 127-146). Rotterdam: Rotterdam University Press.

Coppoolse, R., Van Eijl, P.J., \& Pilot, A. (red.) (2013). Hoogvliegers, ontwikkeling naar professionele excellentie. Rotterdam: Rotterdam University Press.

De Boer, G.C., Minnaert, A.E., \& Kamphof, G. (2013). Gifted Education in the Netherlands. Journal for the Education of the Gifted, 36(1), 133-150.

De Graaf, T. (in press). Evoking Excellence. In M. V. C., Wolfensberger, Volker, J. J. M., \& Drayer, L. (Eds.) (2014). Pursuit of Excellence in a Networked Society - Theoretical and Practical Approaches coming from the Conference Evoking Excellence in Higher Education and Beyond. Munster: Waxman.

Ericsson, K.A. (2004). Deliberate practice and the acquisition and maintenance of expert performance in medicine and related domains. Academic Medicine 79, 70-81.

Györi, J.G. (Ed.) (2012). International horizons of talent support I \& II. Best practices within and without the European Union. Budapest: Géniusz Books.

Haenen, J., \& Mol Lous, A. (2014). Succesfactoren voor passend onderwijs aan hoogbegaafde leerlingen: adviezen voor (aankomende) leerkrachten en opleidingen. Tijdschrift voor Hoger Onderwijs, 31/32(4/1), 66-79.

Harms, L., \& Hogenstijn, M. (2001). The Excellent Tracé. The National Honors Report, 22, 8-10. 
Hermsen, L. \& Coppoolse, R., (2014). Didactische principes voor honoursdocenten bij het begeleiden van honoursstudenten in hun leercurve. Een exploratieve studie. Tijdschrift voor Hoger Onderwijs 31/32(4/1), 93-105.

ITS (2013). Het beste uit studenten. Onderzoek naar de werking van het Sirius-programma om excellentie in het hoger onderwijs te bevorderen. Nijmegen: Radboud Universiteit.

Kazemier, E.M., Offringa, G.J., Eggens, L., \& Wolfensberger, M.V.C. (2014). Motivatie, leerstrategieën en voorkeur voor doceerbenadering van honoursstudenten in het hbo. Tijdschrift voor Hoger Onderwijs 31/32(4/1), 106-123.

Keuning, J. (2014). De dubbellevens van excellente studenten, excelleren in het hbo. Heiloo: Reservaat.

Kool, A., \& Wolfensberger, M.V.C. (2014). Identificatie van excellente studenten. Tijdschrift voor Hoger Onderwijs 31/32(4/1), 80-92.

Korpershoek, H. (2010). Search for Science Talent in the Netherlands. Proefschrift. Groningen: Rijksuniversiteit Groningen.

Long, A. (2012). Editor's introduction. In A. Long (Ed.), Honors around the Globe, Journal of the National Collegiate Honors Council 13, 2, 9-15.

Lutters, J. (2013). Ontwerpgericht onderzoek naar liberal education in het hbo. Cultuur + Educatie 13(37), 54-62.

Marx, B., Elzinga, H., Haaren, M., \& Bastiaens, E. (2014). In Search of the Perfect Evaluation Tool: Discussing Merits and Cons of Different Peer Review Models. Presentation at the annual meeting National Collegiate Honors Council Denver.

OCW (2013, 2 september). Kamerbrief over toptalent in het funderend onderwijs. Den Haag: Ministerie van Onderwijs, Cultuur en Wetenschap.

OCW (2014, 10 maart). Kamerbrief over plan van aanpak toptalenten 2014-2018 toptalent in het funderend onderwijs. Den Haag: Ministerie van Onderwijs, Cultuur en Wetenschap.

Paans, W., Wijkamp, J.S., Wiltens, E., \& Wolfensberger, M.V.C. (2013). What constitutes an excellent allied health care professional? A multidisciplinary focus group study. Journal of Multidisciplinary Health Care, Dove Medical Press, Open Access: 6, 347-356. Geraadpleegd via http://www.dovepress.com/articles.php?article_id=14303.

Platform Bèta-Techniek (2014). Passend onderwijs boven de streep, over excelleren in het primair onderwijs. Den Haag: Platform Bèta-Techniek.

Pleij, H. (2010). 'Moet kunnen'. Een kleine mentaliteitsgeschiedenis van de Nederlander. Diemen: Veen Media.

Pullen, A.G., Griffioen, D.M.E., \& Schoonenboom, J.L. (2013). Abstract NWO project 'Excellent cooperative learning behavior in higher education'. Geraadpleegd via http:// www.nwo.nl/en/research-and-results/research-projects/82/2300176782.html.

Rathenau Instituut (2014). Vizier vooruit, vier toekomstscenario's voor Nederlandse universiteiten. Den Haag: Rathenau Instituut in samenwerking met VSNU.

Sacks, J. (2007). The dignity of difference. How to avoid the clash of civilizations. Londen, UK: Continuum.

Scager, K. (2013). Hitting the high notes, Challenge in teaching honors students. Utrecht: Universiteit Utrecht (unpublished $\mathrm{PhD}$ thesis).

Scager, K., Akkerman, S.F, Keesen, F., Mainhard, M.T., Pilot, A., \& Wubbels, T. (2012). Do honors students have more potential for excellence in their professional lives? Higher Education 64, 1, 19-39, DOI 10.1007/s10734-011-9478-z.

Schutte, I.W., Wolfensberger, M.V.C., \& Tirri, K. (in press). The relationship between ethical sensitivity, high ability and gender in higher education students. Gifted and talented International.

Ten Berge, J.H., \& Van der Vaart, R. (2014). Honoursdidactiek in een leergang voor honoursdocenten. Tijdschrift voor Hoger Onderwijs 31/32(4/1), 37-51. 
Tiesinga, L. (2013). Honours bij de Hanzehogeschool Groningen. Een herijking van de visie op 'honours' als basis voor certificering van honoursprogramma's. Hanzehogeschool Groningen, Hanze Honours College (interne notitie).

Tiesinga, L., \& Wolfensberger, M.V.C. (2014). De cultuur van honoursstudenten en de mogelijke invloed op de reguliere studiecultuur. Tijdschrift voor Hoger Onderwijs 31/32(4/1), 5-19.

Unck, S., Lammers, M., \& Lappia, J. (2014). Dutch Didactics : Honours Pedagogy in the Netherlands. Presentation at the annual meeting National Collegiate Honors Council Denver.

Van Baar, J. (2014). De prestatiegeneratie. Amsterdam: Atlas Contact.

Van den Doel, W. (2007). De stille onderwijsrevolutie. In P.J. van Eijl, M.V.C. Wolfensberger, E.J. Schreve-Brinkman \& A. Pilot, Honours, tool for promoting excellence, Eindrapport van het project Talentontwikkeling in Honours programma's en de meerwaarde die dat oplevert, Mededeling nr. 82. Utrecht: Universiteit Utrecht, IVLOS. Ook gepubliceerd via http://www.rijksoverheid.nl/documenten-en-publicaties/kamerstukken/2007/11/ 13/bijlage-k-rapport-honours-tool-for-promoting-excellence.html.

Van der Rijst, R.M., \& Wolfensberger, M.V.C. (2014). Docentopvattingen over de meerwaarde van honoursonderwijs voor het leren van talentvolle en gemotiveerde studenten. Tijdschrift voor Hoger Onderwijs 31/32(4/1), 52-65.

Van der Valk, T. (in press). Connecting Excellence in Secondary and Higher Education: lessons from Junior College Utrecht. In M. V. C., Wolfensberger, Volker, J. J. M., \& Drayer, L. (Eds.) (2014). Pursuit of Excellence in a Networked Society - Theoretical and Practical Approaches coming from the Conference Evoking Excellence in Higher Education and Beyond. Munster: Waxman.

Van der Valk, T., Grunefeld, H., \& Pilot, A. (2011). Empowerment en leerresultaten van getalenteerde bètaleerlingen in een verrijkte onderwijsleeromgeving. Pedagogische Studiën 88, 73-89.

Van Dijk, T. (2012). The reflective professional honours programme of the Dutch Saxion Universities. Journal of the National Collegiate Honors Council, 1(2), 243-258.

Van Dijk, V., Meijer, F., \& Van der Valk, T. (2013). Excellente leerlingen verkennen elementaire deeltjes. Nederlands Tijdschrift voor Natuurkunde, 79 (6), 216-220.

Van Eijl, P., Pilot, A., Wolfensberger, M.V.C., \& Schreve-Brinkman, E.J. (2010). Talentontwikkeling in honoursprogramma's: een verkenning. Tijdschrift voor Hoger Onderwijs, 28(4), 182-198.

Van Eijl, P., Wolfensberger, M.V.C., \& Van Tilborgh, P. (2004). Honoursprogramma's in Nederland. Voorlopige resultaten van een landelijke inventarisatie. Mededeling 77. Utrecht: Universiteit Utrecht, IVLOS.

Van Eijl, P.J., Faber, G., Jorissen, M.G.A., \& Pilot, A. (1999). Een honorsprogramma in Nederland. Tijdschrift voor Hoger Onderwijs, 17(4), 274-288.

Van Eijl, P.J., Koertshuis, Van den Berg, E., Spil, S., Kingma, T., Coppoolse, R., \& Pilot, A. (2013). Latent talent ontdekken en betrekken bij honoursonderwijs. In R. Coppoolse, P.J. van Eijl \& A. Pilot (red.), Hoogvliegers, ontwikkeling naar professionele excellentie (pp. 35-56). Rotterdam: Rotterdam University Press.

Van Eijl, P.J., Pilot, A., \& Heemskerk, R., (2013). Kwaliteitszorg voor Honoursprogramma's. In R. Coppoolse, P.J. van Eijl \& A. Pilot (red.), Hoogvliegers, ontwikkeling naar professionele excellentie (pp.195-208). Rotterdam: Rotterdam University Press.

Van Eijl, P.J., Pilot, A., \& Wolfensberger, M.V.C. (Eds.) (2010). Talent voor morgen. Ontwikkeling van talent in het hoger onderwijs. Groningen: Noordhoff Uitgevers.

Van Eijl, P.J., Renique, C., \& Reimer, P. (2011). Werken aan excellentie. Tijdschrift voor Hoger Onderwijs \& Management, 4, 10-15. 
Van Eijl, P.J., Wolfensberger, M.V.C., Cadee, M., Pilot, A. Siesling, S., Schreve-Brinkman, E.J., Beer, W.M., Faber, G. (2004). Plusprogramma's als proeftuin, met als bijlage een inventarisatie van plusprogramma's in Nederland. Mededeling 69. Utrecht: Universiteit Utrecht, IVLOS.

Van Ginkel, S., Van Eijl, P.J., \& Pilot, A. (2014). Honourscommunity, een stimulans voor excellentie. Tijdschrift voor Hoger Onderwijs 31/32(4/1), 20-36.

Van Ginkel, S., Van Eijl, P.J., Pilot, A., \& Zubizarreta, J. (2012). Honors in the Master's: A New Perspective? Journal of the National Collegiate Honors Council 13(2), 265-278.

Van Gorp, B., Wolfensberger, M.V.C., \& De Jong, N.A. (2012). Setting them free: Students as co-producers of honors education. Journal of the National Collegiate Honors Council, 13(2), 183-195.

Van Tassel-Baska, J. (2013). Quest Editor's Commentary. Journal for the Education of the Gifted, 36(1), 3-5.

Van Wissen, G.J.M., \& Wolfensberger, M.V.C. (2006). Wenselijkheid van honoursprogramma's aan juridische faculteiten in Nederland. Ars Aequi, 929-934.

Vansteenkiste, M., Sierens, E., Goossens, L., Soenens, B., Dochy, F., Mouratidis, A., Aelterman, N., Haerens, L., \& Beyers, W. (2012). Identifying configurations of perceived teacher autonomy support and structure: Associations with self-regulated learning, motivation and problem behavior. Learning and Instruction, 22, 431-439.

Wiegant, F., Scager, K., \& Boonstra, J. (2011). An Undergraduate Course to Bridge the Gap between Textbooks and Scientific Research. CBE-Life Sciences Education, 10, 83-94.

Wijffels, H., \& Wolfensberger, M.V.C. (2004). Wat vraagt de samenleving van talent? Hoe universiteiten daarop in kunnen spelen. Tijdschrift voor Hoger Onderwijs \& Management (Thema) 11(1), 51-54.

Wolfensberger, M.V.C. (2011). Excelleren in hoger onderwijs en samenleving: een integratief model rondom uitmuntende prestaties. Onderzoek van Onderwijs, 40(3), 44-51.

Wolfensberger, M.V.C. (2012). Teaching for excellence. Honors pedagogies revealed. Münster: Waxmann.

Wolfensberger, M.V.C., De Jong, N., \& Drayer, L. (2012). Leren excelleren, Excellentieprogramma's in het $H B O$, een overzicht. Groningen: Hanzehogeschool.

Wolfensberger, M.V.C., Sweijen, S., Van Eijl, P., Hartog, M., \& Van der Vaart, R. (2010). Honours alumni over de meerwaarde van hun honours onderwijs. Tijdschrift voor Hoger Onderwijs, 28(4), 199-216.

Wolfensberger, M.V.C., Van Eijl, P.J., \& Pilot, A. (2003). Universitaire Honours Programma's en hun innovatieve functie. Tijdschrift voor Hoger Onderwijs 21(2) 85-102.

Wolfensberger, M.V.C., Van Eijl, P.J., \& Pilot, A. (2012). Laboratories for Educational Innovation: Honors Programs in the Netherlands. Journal of the National Collegiate Honors Council 13(2), 149-170.

Wolfensberger, M.V.C., Van Eijl, P.J., Cadee, M., Pilot, A. Siesling, S., \& Schreve-Brinkman, E.J. (2003). Plusprogramma's, ook een strategie voor onderwijsvernieuwing. Tijdschrift voor Hoger Onderwijs \& Management 10(5), 44-51.

Zander, B. \& Stone-Zander, R. (2002). The art of possibility. Transforming Professional and personal life. London: Penguin Books Ltd. 